\title{
Measuring the Impact of Road Rehabilitation on Spatial Market Efficiency in Maize Markets in Mozambique
}

Cirera, Xavier; Arndt, Channing

Published in:

Agricultural Economics

DOI:

10.1111/j.1574-0862.2008.00311.x

Publication date:

2008

Document version

Publisher's PDF, also known as Version of record

Citation for published version (APA):

Cirera, X., \& Arndt, C. (2008). Measuring the Impact of Road Rehabilitation on Spatial Market Efficiency in Maize Markets in Mozambique. Agricultural Economics, 39(1), 17-28. https://doi.org/10.1111/j.1574-0862.2008.00311.x 


\title{
Measuring the impact of road rehabilitation on spatial market efficiency in maize markets in Mozambique
}

\author{
Xavier Cirera ${ }^{\mathrm{a}, *}$, Channing Arndt $^{\mathrm{b}}$ \\ ${ }^{a}$ Institute of Development Studies, University of Sussex, Brighton BN1 4RE, United Kingdom \\ ${ }^{\mathrm{b}}$ Department of Agricultural Economics, Purdue University, West Lafayette, IN 47907, USA
}

Received 20 November 2006; received in revised form 22 May 2007; accepted 13 September 2007

\begin{abstract}
This article analyzes the impact of road rehabilitation on the spatial market efficiency of maize markets in Mozambique. We estimate a modified version of the Parity Bounds Model (PBM) that allows us to test the impact of road rehabilitation on spatial efficiency. This article seeks to contribute to the existing literature in three ways. First, a unique data set, where road rehabilitation episodes between market pairs are identified, is developed. Second, special care is devoted to estimation of transaction costs due to the sensitivity of the PBM model to the quality of transaction costs estimates. Finally, as opposed to most existing literature that focuses on relatively distant markets, the article focuses on spatially closed markets. We find that maize markets tend to be segmented due to high transport costs. Following road rehabilitation, inefficiency and average absolute price differentials tend to decrease, and market pairs have tended to shift toward autarky regimes. Overall, while the results point broadly toward a positive impact of road rehabilitation on spatial efficiency, they are not as strong or as robust as one would like. Large increases in fuel prices likely offset the positive impacts of road rehabilitation on transaction costs, contributing to the increase in the probability of being in an autarky regime.
\end{abstract}

JEL classification: F14, Q13

Keywords: Maize markets; Mozambique; Spatial arbitrage; Road rehabilitation; Parity Bounds Model

\section{Introduction}

Spatial market efficiency is a key element for policy transmission and effectiveness. Well-functioning markets are crucial to ensuring the desired impact of different economic policies, such as macroeconomic or trade policy. Spatially segmented markets isolate economic agents and households across space, limiting the transmission of price incentives and the resulting positive welfare impact in terms of lower prices and increased product availability.

Traditionally, Mozambican provinces have tended to be poorly integrated due to high transport costs (Penzhorn and

\footnotetext{
*Corresponding author: Tel.: +(44)(0)1273-87(7749); fax: +(44)(0)1273-
} 621202/691647. E-mail address: X.Cirera@ids.ac.uk (X. Cirera).

\section{Data Appendix Available Online}

A data appendix to replicate main results is available as part of the online article from: www.blackwell-synergy.com (this link will take you to the article abstract). Please note: Blackwell Publishing is not responsible for the content or functionality of any supplementary materials supplied by the authors. Any queries (other than missing material) should be directed to the corresponding author for the article.
Arndt, 2002; Tostao and Brorsen, 2005). The road network was seriously damaged during a decade-long civil war that ended in 1992. In addition, the war prevented any substantial investment in rehabilitation and maintenance as well as new road construction. The inadequacy of the road network makes transport along the $2,500 \mathrm{~km}$ distance from North to South of the country extremely costly, increasing the likelihood of market segmentation.

Since the end of the war in 1992, the country has experienced significant liberalization and high growth rates. ${ }^{1}$ Anecdotal evidence indicates that growth has helped fuel an increase in the number of participants in trading activities. At the same time, very substantial investments in new roads and road rehabilitation have occurred.

This article attempts to measure the extent of spatial efficiency in Mozambique. It seeks to contribute to the existing literature in three ways. First, we employ a unique data set that contains price observations and detailed information on road

\footnotetext{
${ }^{1}$ See Tarp et al. (2002) for a detailed overview of the liberalization process in Mozambique.
} 
construction and road rehabilitation. This information allows us to consider specifically the impact of road rehabilitation on maize price patterns. Second, a great deal of attention is devoted to obtaining the best possible transaction cost estimates, which increases the robustness of the results. Third, existing work on market integration in Mozambique has focused on linkages between relatively distant markets (usually more than $500 \mathrm{~km}$ apart). Here, the focus is on market pairs that are less disparate spatially. The distances separating the market pairs analyzed range from 24 to $243 \mathrm{kms}$.

The approach relies on differences in maize prices as an indicator of market arbitrage, following an extension of the Parity Bounds Model (PBM) methodology similar to Park et al. (2002) or Negassa et al. (2003). The advantage of using locally produced white maize as the reference good is that it is relatively homogeneous with widespread demand. These characteristics permit comparison across markets in the country.

The article is organized as follows. Section 2 defines the concept of spatial market efficiency. Section 3 describes the situation of the maize sector in Mozambique. Section 4 describes the methodology and the data. Section 5 analyzes the impact of road rehabilitation on spatial arbitrage on selected provincial market pairs. The final section concludes.

\section{Spatial market integration and efficiency}

Market integration is at the heart of welfare analysis in economics. Markets gather together demand and supply across actors that are located in different points of geographical space. In well-integrated markets, regions with excess supply are able to transfer production to regions with excess demand, responding to price signals. In the international domain, the impact of monetary, exchange rate, or trade policy depends on how well markets are integrated and whether prices tend to equalize. In the national domain, any macroeconomic policy (monetary, fiscal, trade, infrastructure, or technology) is mainly transmitted by changes in relative prices. If markets of the same country are segmented with limited price transmission, economic policy becomes less effective.

As an example, consider the case of trade reform. In the short run, a change in relative prices of tradable to nontradable goods will create adjustment in demand and supply of these goods. However, the price change is observed at the border. The implications of trade reform, therefore, depend on the degree of market integration. In the case of segmented markets, trade reform may alter consumer behavior and foster specialization in firms located near the border, while leaving rural areas, often poorer and more populated, largely unaffected.

Integration has traditionally been associated with the "Walrasian" concept of transfer of excess demand from one market to another via trade flows, price shocks, or both. Under this tradability view, trade flows are sufficient to signal spatial market integration, but do not necessarily imply price equalization, which is consistent with inefficient Pareto distributions (Barrett, 2008). A second approach, based on Baumol's work on con- testable markets, focuses instead on the full exploitation of arbitrage rents and competitive markets. Under this second approach to spatial market integration, two markets are integrated when there are zero marginal profits to arbitrage, leaving agents indifferent about trading, and therefore, reaching a competitive equilibrium and a Pareto efficient distribution (Barrett and $\mathrm{Li}$, 2002). (For a general discussion on the different distinctions regarding the meaning of market integration see Fackler and Goodwin, 2002.)

These approaches to market integration are related but not identical. Under the first approach, trade is sufficient but not necessary for market integration. Two markets can be integrated by belonging to a network or by having a state trading institution that fixes prices in response to regional or national shocks. In these cases, price shocks are transmitted even in the absence of trade. On the other hand, under the spatial efficiency approach, efficiency can be achieved without observing trade between two locations if there are no marginal profits to arbitrage. This is especially the case in the presence of high transaction costs.

The existing literature has tended to focus more on the spatial efficiency approach to market integration. This is due in part to the theoretical reasons suggested above (Pareto efficiency, competitive markets, and the fact that observing trade is not a sufficient condition for efficiency). Practical reasons also play a role as price data across space tend to be more readily available than trade flow data between market pairs. This article follows the spatial efficiency approach to market integration.

\section{Maize markets and spatial market efficiency in Mozambique}

\subsection{The maize sector in Mozambique}

The production of maize in Mozambique occurs mainly on small family plots. Production is not evenly distributed across the country. Provinces in the central and northern region often produce maize surpluses, which are exported to the south and to Malawi. ${ }^{2}$ Provinces in the south are net consumers and import maize, mainly from South Africa but also from the central region. Production has trended upward relatively slowly since 1996 , with variation due mainly to climate shocks. For example, in 2000 there were maize production shortages due to widespread flooding, which resulted in significant increases in nominal and real market prices of maize (See Fig. 1). From 2002, annual average prices have remained relatively stable. Fig. 2 illustrates clear positive correlations between nominal monthly maize prices across major markets.

State involvement in maize marketing used to be significant. $^{3}$ The maize marketing system was characterized by a

\footnotetext{
2 Informal exports to Malawi were estimated at around 71,000 tones between July 2004 and March 2005.

${ }^{3}$ Agricultural prices, the main instrument of government intervention (see Tarp, 1990), were liberalized in the early 1990s.
} 


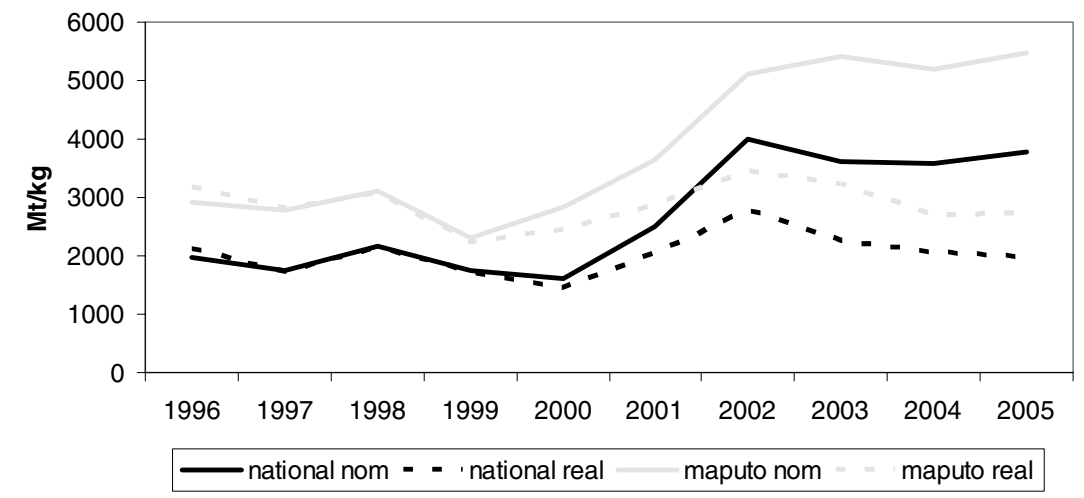

${ }^{a}$ National average is calculated using prices in main provincial markets. Real prices obtained by deflating nominal prices with the consumer price index.

Fig. 1. Evolution of annual average nominal and real white maize price $(\mathrm{Mt} / \mathrm{kg})^{\mathrm{a}}$.

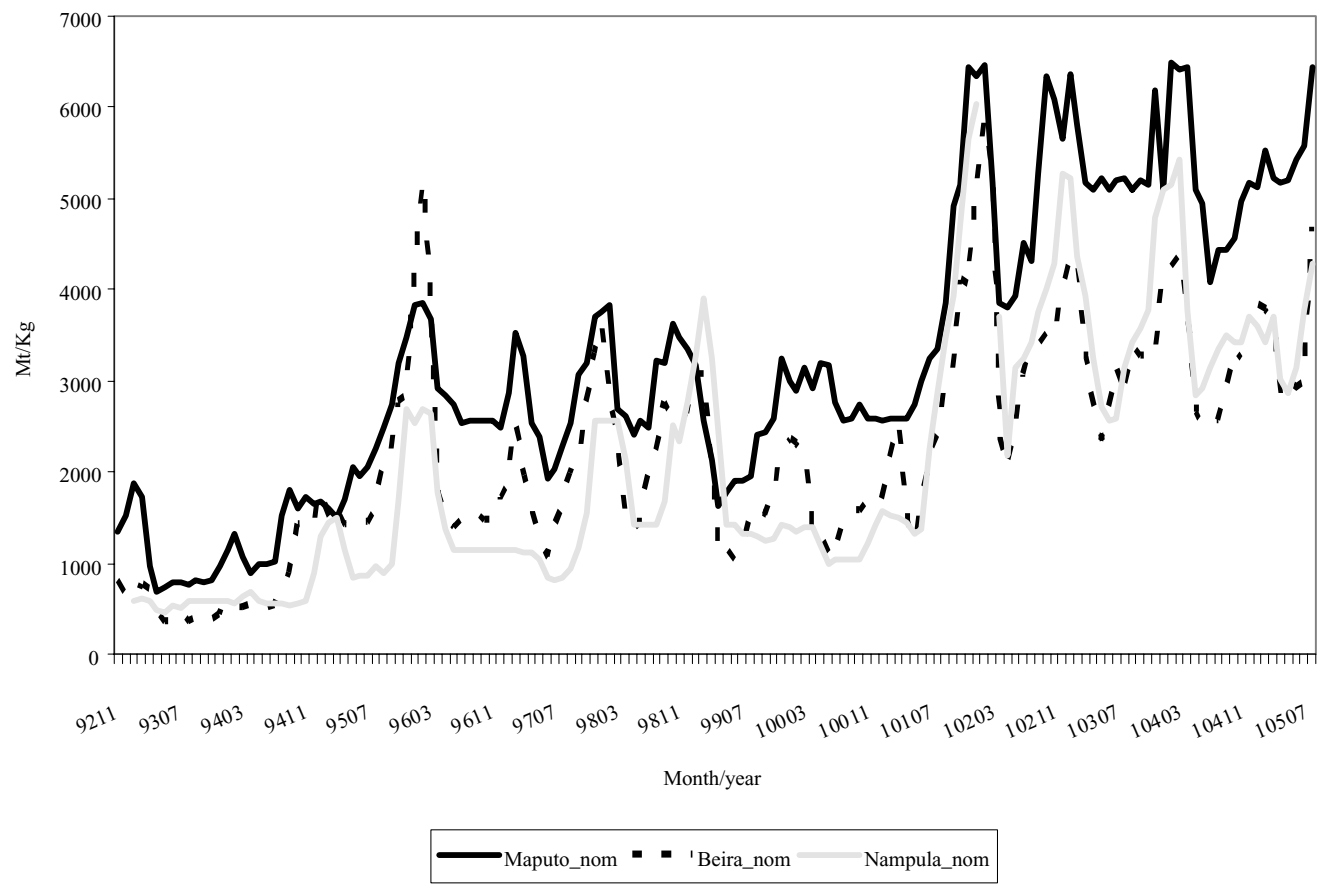

Fig. 2. Nominal monthly maize prices for major urban markets.

parastatal monopsony, the Instituto dos Cereais de Moçambique (ICM), which carried out its last intervention in 1999 (see Cirera and Arndt, 2006, for a more detailed explanation). Since 1996, a few large private traders started operating in the central and northern regions. Nevertheless, commercialization remains largely within the realm of informal traders. The World Food Programme (2005) suggests that, overall, informal traders commercialize larger volumes than formal traders. The important role of informal traders may affect spatial arbitrage and competition. Specifically, informal traders may be more sensitive to transport costs as they often do not own their own transport equipment.

At first sight, spatial markets in Mozambique seem to be segmented by poor infrastructure. Regarding road infrastructure,
$53 \%$ of roads are nonpaved tertiary roads that connect districts. Of the remaining, $16 \%$ are primary roads and $31 \%$ are secondary roads. These have been progressively rehabilitated in the last 10 years (MIC, 2001) though road conditions remain far from perfect (Jacobs Consultancy, 2005). On the other hand, maritime transport, a seemingly natural and potentially cheaper way of transporting goods from North to South, is expensive, with the added problem of lack of vessel availability and low frequency of services between main Mozambican ports (MIC, 2001). ${ }^{4}$

\footnotetext{
${ }^{4}$ Very often vessels do not leave port until they are at full capacity.
} 


\subsection{Evidence of spatial market efficiency in maize markets in Mozambique}

There are several studies on spatial efficiency in maize markets in Mozambique. A detailed study by Donovan (1996) that focuses on the evolution of maize prices found significant price linkages between maize markets in Maputo and Chimoio. For the same market pair, Penzhorn and Arndt (2002) estimate a PBM and found that the probability of spatial efficiency is around $75 \%$, while the probability of spatial inefficiency is around 22\%. Tostao and Brorsen (2005) estimate the PBM for 13 market pairs and find that markets are mostly spatially efficient, but high transport costs impede integration. Abdula (2005), using a cointegration approach, finds that integration is relatively weak, price shocks are not fully transmitted, and there is on average two weeks delay in the transmission of shocks. Thus, existing evidence seems to suggest that maize markets tend to be spatially efficient; however, integration is still very limited due to high transaction costs.

\section{Methodology and data}

A large amount of investment has been oriented toward significant road rehabilitation. As suggested by existing evidence on spatial market efficiency in Mozambique, spatial efficiency is seriously constrained by high transport costs. Thus, we should expect that substantial road rehabilitation could impact positively the likelihood of becoming more efficient.

\subsection{Methodology: extended PBM}

Several methodologies have been used for analyzing spatial arbitrage or spatial price analysis. Fackler and Goodwin (2002) provide a detailed overview. In this article we employ the PBM methodology.

The PBM is a model based on the importance of transaction costs when analyzing spatial price efficiency. This methodology estimates by maximum likelihood a switching regression model for the three regimes predicted by the Enke-SamuelsonTakayama-Judge model (Samuelson, 1952; Takayama and Judge, 1971), namely: efficiency, segmented efficiency, and inefficiency (represented by Eqs. (1), (2), and (3) below). This model accommodates time-varying transaction costs, trade reversals, and the situation of autarky (Baulch, 1997; Sexton et al., 1991 Spiller and Wood, 1988).

As suggested by the Enke-Samuelson-Takayama-Judge model, price differentials between two markets for an identical good depend on the size of transaction costs between the two locations. Thus, spatial market integration can be characterized by the three regimes described by Eqs. (1) to (3), where the price difference of good $a$ in markets $i$ and $j$ depends on transaction costs of good $a$ between market $i$ and $j, \delta_{i j t}$, and random components $e_{t}, u_{t}$, and $v_{t}$.

$\left|P_{i t}-P_{j t}\right|=\delta_{i j t}+e_{t}$,
$\left|P_{i t}-P_{j t}\right|=\delta_{i j t}+e_{t}-u_{t}$,

$\left|P_{i t}-P_{j t}\right|=\delta_{i j t}+e_{t}+v_{t}$

Regime I in Eq. (1) represents spatially efficient markets. This regime is at the parity bounds. Price differences, between $i$ and $j$, equal transaction costs in period $t, \delta_{i j t}$, plus a normally distributed error term component, $e_{t}\left(0, \sigma_{e}^{2}\right)$. The error term captures unexplained variation at the parity bounds due to, for example, unexplained variation in transaction cost estimates. This regime is equivalent to the law of one price, profits are maximized, and there is competitive equilibrium, with or without the presence of trade flows.

Regime II in Eq. (2) represents the autarky regime, where price differentials are below transaction costs and hence inside the parity bounds. The error term $u_{t}$ is semitruncated positive, and measures by how much the prices fall short of the parity bounds. This regime does not imply inefficiency, since arbitrage is not profitable; however, it is associated with a lack of spatial integration. Prices may be uncorrelated within a band of high transaction costs that make arbitrage profits negative.

Finally, Regime III in Eq. (3) represents spatially inefficient markets, where price differentials are above transaction costs. The semitruncated positive error term $v_{t}$ measures by how much the price differences exceed transaction costs. The errors, $u_{t}$ and $v_{t}$, are associated with demand and supply conditions, respectively. This regime implies the existence of unexploited arbitrage rents due to lack of information, barriers to entry, market power, or trade quotas. In this case, some trade may or may not occur. If trade occurs, then, under the tradability approach, there is some degree of integration between markets, but the markets are not competitive. Under the efficiency approach to market integration, however, Regime III, spatial inefficiency, is considered as evidence of lack of integration (Baulch, 1997).

The PBM approach has several well-known weaknesses (Negassa et al., 2003). First, it ignores the time-series properties of price and transaction cost data. Second, the distributional assumptions of the variables are not based on economic theory, and the results of the estimation depend on these assumptions. Third, short-term deviations from equilibrium that are the result of rational lagged adjustment are treated as inefficiency.

Despite these limitations, the PBM remains a frequently used approach for spatial price analysis. The PBM methodology has been extended by Barrett and $\mathrm{Li}$ (2002) to add trade flows and improve market integration analysis. Moser et al. (2005) apply the basic approach to the study of integration in time and form for the case of rice in Madagascar. Finally, the PBM model allows estimation of transaction costs endogenously (Park et al. 2002).

Given data on price differences and transaction costs estimates, we estimate for every period $t$ the probability of being in the three regime bands: the parity bound, inside, or above. These bands are determined by the variance of the error terms; 
$\sigma_{e}^{2}$ for Regime I, $\sigma_{e}^{2}+\sigma_{u}^{2}$ for Regime II, and $\sigma_{e}^{2}+\sigma_{v}^{2}$ for Regime III (assuming the errors are uncorrelated). Therefore, a key in the model is the quality of transaction costs estimates, $\delta_{i j t}$, whether they are exogenously or endogenously estimated. Choosing the right transaction costs estimates will determine the degree of robustness of regime probability estimates (see Section 4.3.2).

In order to estimate the probability of being in one regime or another, we need to define the likelihood function in Eq. (4) given the $f_{\mathrm{rt}}$ density functions for every regime (Eqs. (5) to (7)), where $\Phi()$ is the standard normal density function and $\phi()$ is the cumulative distribution function. Equation (11) is maximized to obtain estimates of the parameter vector $\vartheta$ that contains $\sigma_{e}, \sigma_{u}$, $\sigma_{v}, \lambda_{1 t}, \lambda_{2 t}, \lambda_{3 t}$, and, when estimated endogenously, transaction $\operatorname{costs} \delta_{i j t}$.

$$
\begin{aligned}
f_{t}\left(\rho_{t} \mid \vartheta\right)= & \lambda_{1} f_{1 t}\left(\rho_{t} \mid \vartheta\right)+\lambda_{2} f_{21 t}\left(\rho_{t} \mid \vartheta\right) \\
& +\left(1-\lambda_{1}-\lambda_{2}\right) f_{3 t}\left(\rho_{t} \mid \vartheta\right),
\end{aligned}
$$

where $\rho_{t}=\Delta p_{i j t}-\delta_{j i t}$.

$f_{1 t}=\frac{1}{\sigma_{e}} \phi\left[\frac{\left|P_{i t}-P_{j t}\right|-\delta_{j i t}}{\sigma_{e}}\right]$,

$$
\begin{aligned}
f_{2 t}= & {\left[\frac{2}{\left(\sigma_{e}^{2}+\sigma_{u}^{2}\right)^{1 / 2}}\right] \phi\left[\frac{\left|P_{i t}-P_{j t}\right|-\delta_{j i t}}{\left(\sigma_{e}^{2}+\sigma_{u}^{2}\right)^{1 / 2}}\right] } \\
& \times\left[1-\Phi\left[\frac{\left(\left|P_{i t}-P_{j t}\right|-\delta_{j i t}\right) \frac{\sigma_{u}}{\sigma_{e}}}{\left(\sigma_{e}^{2}+\sigma_{u}^{2}\right)^{1 / 2}}\right]\right],
\end{aligned}
$$

$$
\begin{aligned}
f_{3 t}= & {\left[\frac{2}{\left(\sigma_{e}^{2}+\sigma_{v}^{2}\right)^{1 / 2}}\right] \phi\left[\frac{\left|P_{i t}-P_{j t}\right|-\delta_{j i t}}{\left(\sigma_{e}^{2}+\sigma_{v}^{2}\right)^{1 / 2}}\right] } \\
& \times\left[1-\Phi\left[\frac{\left(\left|P_{i t}-P_{j t}\right|-\delta_{j i t}\right) \frac{\sigma_{v}}{\sigma_{e}}}{\left(\sigma_{e}^{2}+\sigma_{v}^{2}\right)^{1 / 2}}\right]\right],
\end{aligned}
$$

$L=\prod_{t=1}^{T} \lambda_{1 t} f_{1 t}+\lambda_{2 t} f_{2 t}+\left(1-\lambda_{1 t}-\lambda_{2 t}\right) f_{3 t}$

In the original PBM formulation, single estimates of regime probabilities are obtained for the full estimation period. We modify the original PBM model in order to permit efficiency changes (as represented by changes in regime probabilities) over time due to generalized trends in market efficiency or specific policy interventions such as road construction/rehabilitation. Concretely, we follow the methodology proposed by Park et al. (2002) and Negassa et al. (2003) by making the probabilities of belonging to any of the regimes dependent on time-variant variables (see Eqs. (9) and (10)). Here $T t$ is a dummy variable that measures the introduction of road rehabilitation. Thus, coefficients $\gamma_{1}$ and $\gamma_{3}$ measure the impact on the period probability associated with the introduction of road rehabilitation.

$\lambda_{1 t}=\gamma_{0}+\gamma_{1} T_{t}$,

$\lambda_{2 t}=\gamma_{2}+\gamma_{3} T_{t}$.

\subsection{Data}

The primary source of data is the agricultural market information system (SIMA, 2005) database from the Ministry of Agriculture. This database provides information on prices of major agriculture products in more than 30 markets spread throughout the country. The frequency is weekly since 1993, but there exists a significant number of missing observations for some markets, especially at the beginning of the period. The absolute value of the price difference has been used as a measure of the price spread. Price differences are deflated using the monthly consumer price index (CPI) available from the National Institute of Statistics (INE), in order to remove any general trends in maize prices and permitting focus on real transport costs.

There are two main sources for transport cost observations. MIC (2001) carried out a survey on transport costs for maize for some market pairs in 2001. In addition, the SIMA database has collected data on maize transport costs for some market pairs during some periods. Finally, data on road rehabilitation, number of kilometers rehabilitated, and date when road works were completed were gathered from the Administração Nacional de Estradas (ANE).

\subsection{The impact of road rehabilitation on spatial arbitrage}

We expect road rehabilitation to impact spatial arbitrage via two channels. The first and main channel is by lowering transport costs, and therefore transaction costs. Road improvement reduces the hazards and time length of road transport and therefore this should be translated into more transport services available and a reduction of transport costs. Second, road enhancement is likely to facilitate the entry to the market of more traders, especially informal traders that lack transport capacity. Entry of new traders may increase competition and arbitrage, reduce price spreads, and therefore potentially improve spatial efficiency and integration. ${ }^{5}$

\footnotetext{
${ }^{5}$ These informal traders tend to depend on the availability of trucks and vans working on that route, often returning empty after delivering their load. We should expect that better road conditions increase the amount of vehicles transporting goods on the area.
} 
Table 1

Markets selected and road rehabilitated

\begin{tabular}{|c|c|c|c|c|}
\hline Markets & Province & Section rehabilitated & Market pairs distance & Finished \\
\hline Beira-Chimoio & Sofala/Manica & Beira-Inchope (Nhamatanda) & 134 & Oct-99 \\
\hline Manica-Chimoio & Manica & Inchope-Machipanda & 154 & Jun-97 \\
\hline Nampula-Nacala & Nampula & Nampula-Nacala & 199 & Nov-04 \\
\hline Pemba-Montepuez & Cabo Delgado & Pemba-Montepuez & 243 & Jun-02 \\
\hline Tete-Chimoio & Tete/Manica & Partly finished & & Dec-02 \\
\hline Chockwe-Xai-Xai & Gaza & Macia-Chockwe & 62 & Aug-98 \\
\hline
\end{tabular}

Source: Authors own elaboration based on information from Roads National Authorities (ANE).

Table 2

Transport costs observations for selected pair of markets

\begin{tabular}{|c|c|c|c|c|c|c|c|c|}
\hline & \multicolumn{7}{|c|}{ SIMA } & \multirow[t]{2}{*}{ MIC } \\
\hline & Obs & Before rehab & After rehab & Mean & Std. Dev. & Min & Max & \\
\hline Beira-Chimoio & 22 & 22 & 0 & 416.23 & 124.87 & 228.57 & 857.14 & No \\
\hline Manica-Chimoio & 9 & 9 & 0 & 230.16 & 122.57 & 142.86 & 500 & No \\
\hline Nampula-Nacala & 16 & 14 & 2 & 337.05 & 110.63 & 214.29 & 642.86 & Yes \\
\hline Pemba-Montepuez & 88 & 15 & 73 & 473.21 & 116.30 & 142.86 & 857.14 & Yes \\
\hline Tete-Chimoio & 28 & 14 & 8 & 681.12 & 186.95 & 428.57 & $1,285.71$ & No \\
\hline Xai-Xai-Chockwe & 18 & 18 & 0 & 428.57 & 183.34 & 214.29 & 714.29 & Yes \\
\hline
\end{tabular}

Note: Costs are in nominal Metical per kilogram (24,000 Metical/USD).

Source: SIMA and MIC (2001).

\subsubsection{Choice of market pairs.}

In order to choose market pairs, we have focused on roads that experienced significant rehabilitation. The pairs selected are mainly markets belonging to the same province or to neighboring provinces. Practicalities prevent focus on more distant market pairs as it is very difficult to find cases of distant markets where a substantial part of the road has been rehabilitated. Also, as indicated above, most of the existing analysis of market integration in Mozambique focuses on relatively distant markets. This article contributes to the literature by studying spatial efficiency for intraprovincial (or close) market pairs with special accounting for periods before and after road rehabilitation. Table 1 summarizes selected market pairs and the extent of road rehabilitation in these selected routes. ${ }^{6}$

\subsubsection{Transaction costs.}

One of the main weaknesses of the PBM methodology is that it is highly dependent on the quality of transaction cost estimates. Since transport costs are the main component of transaction costs, reliable transport cost information is particularly important as the impact of road rehabilitation on spatial market arbitrage is expected to be transmitted via a reduction in transport costs.

\footnotetext{
${ }^{6}$ For the case of Xai-Xai-Chockwe, even though the road works carried out were considered as maintenance, improvements in road conditions were substantial. In addition, the rehabilitation of the route Tete-Chimoio was only partial, but substantial improvements were achieved.
}

Unfortunately, as in many other developing countries, transaction and transport cost data are scarce. The main source for transport costs data is provided by SIMA, but these data are only available from 2001 and with relatively light frequency (See Table 2). Due to the paucity of data, we resort to using existing information to predict transaction costs values for most of the estimation period. We predict transport costs using existing observations inflated by a constant percentage that accounts for the mark-up/commercialization and other commercialization costs (see Table 3). The lack of observations before 2001 implies that we cannot test directly whether road rehabilitation had an impact on transport costs in cases where road works were completed before $2001 .^{7}$ As a result, we focus mainly on observed price differentials before and after road rehabilitation.

In addition, in order to overcome the problem of a potential lack of robustness of transaction costs ${ }^{8}$ we first predict different sets of transaction cost. This approach, based on sensitivity analysis, allows us to, first, choose the estimates that are more similar to observed data and existing qualitative information, and, second, to identify the impact on the degree of spatial efficiency under "best" transaction cost calculation

\footnotetext{
${ }^{7}$ As Tables 2 and 4 show, for the market pairs Nampula-Nacala, PembaMontepuez, and Tete-Chimoio, road rehabilitation occurs after 2001 and therefore there is some SIMA data available. In all three cases, however, average transport costs are higher after road rehabilitation. This is quite likely to be the result of high diesel prices.

${ }^{8}$ Lack of robustness of transaction costs estimates implies lack of robustness in the estimation of regime probabilities.
} 
Table 3

Description of transaction costs estimates

\begin{tabular}{|c|c|}
\hline Specification & Description \\
\hline MIC & $\begin{array}{l}\text { For markets with one MIC (2001) observation available, we have constructed a series deflating the observation } \\
\text { with diesel prices and adding a fixed mark-up of 33\%, as suggested by MIC (2001) as a constant } \\
\text { commercialization mark-up. This method has been used in other papers such as Penzhorn and Arndt (2002) } \\
\text { and Tostao and Brorsen (2005). }\end{array}$ \\
\hline \multirow[t]{2}{*}{ SIMA (SIMA1 and SIMA2) } & $\begin{array}{l}\text { For markets with several observations from the SIMA database, we use the following equation and regress the } \\
\text { existing observations on a constant, diesel prices, and a dummy with value } 1 \text { for the months of } \\
\text { commercialization. The predicted values are used as transaction costs estimates. When the observations cover } \\
\text { the period before and after road rehabilitation, the road rehabilitation dummy, a variable with value } 1 \text { after } \\
\text { rehabilitation and } 0 \text { otherwise, is also added to the regression. }\end{array}$ \\
\hline & $T C_{i j t}=\beta_{0}+\beta_{1}$ DIESEL $_{t}+\beta_{2}$ COMER $_{t}+\beta_{3} R O A D_{i j t}+e_{i j t}$ \\
\hline Est1 & This specification estimates constant transaction costs endogenously in the model, Eqs. (4)-(8). \\
\hline Est2 & $\begin{array}{l}\text { The fourth specification incorporates the equation above to the model and estimates transaction costs } \\
\text { endogenously but controlling for the impact of diesel prices, commercialization period, and road } \\
\text { rehabilitation. }\end{array}$ \\
\hline $\mathrm{TC}$ & $\begin{array}{l}\text { The fifth specification is based on the predicted values arising from estimating a panel with all the SIMA data } \\
\text { available; this includes more than } 100 \text { market pairs and 3,872 observations. We estimate the following } \\
\text { equation, where transport costs are a function of distance, diesel prices, and a dummy for commercialization } \\
\text { months, as a random effects model, and predict transport costs for all the market pairs of interest, inflated with } \\
\text { a 30\% mark-up. }\end{array}$ \\
\hline & $T C_{i j t}=\beta_{t}+\beta_{1} D I S T_{i t}+\beta_{2} D I E S E L_{t}+\beta_{3} C O M E R_{t}+e_{i j t}$ \\
\hline TC2 & $\begin{array}{l}\text { The last specification computes the yearly averages with the SIMA information available from } 2001 \text { to } 2005 \text {, } \\
\text { with a } 30 \% \text { mark-up. Then, it applies the average growth rate for this period in order to obtain values from } \\
1995 \text { to } 2000 \text {. This specification is only used for market pairs with data available, and applied for monthly } \\
\text { specifications since it only has yearly variations. }\end{array}$ \\
\hline
\end{tabular}

methodologies. To our knowledge, this is novel in the literature, which tends to use one single set of endogenous or exogenous estimates.

Concretely, seven sets of transaction costs series are initially estimated from the information available. Table 3 summarizes the methodologies used, which range from constant costs endogenously estimated within the PBM estimation framework to a pooled panel equation estimation relying on existing transport cost data. Table 2 summarizes data availability for each market pair regarding transport costs. These series of transaction costs estimates are plotted for each market pair in Fig. 3.

The panel estimation approach uses data for all routes in the country where information is available. We estimate the model with random effects. The variables of interest-distance, diesel prices, and commercialization/dry season dummy - are statistically significant at $95 \%$ confidence level and have the correct sign; and the overall $R^{2}$ is 0.53 . For the routes of interest to this study (routes where road rehabilitation occurred), examination of the residuals reveals a consistent pattern of positive error terms (e.g., estimates tend to be larger than observed data). This may be due to the fact that the intraprovincial routes in focus here have lower transport costs due to higher transport flows compared with the full set of transport routes in the country.

In contrast to the panel estimates, the endogenous estimates derived directly from the PBM framework tend to underestimate transaction costs as compared with observed transaction costs (see Fig. 3), and, therefore, seem to be biased against identifying autarky regimes (and hence toward identifying efficient and inefficient regimes).
Due to these significant discrepancies between the different transaction costs series, we use those estimates that are closer to collected transport costs observations: SIMA and TC2. SIMA estimates are constructed estimating the reduced-form equation in Table 3 for every specific route. Predicted values are closer to existing observations for the cases of Beira-Chimoio, Manica-Chimoio, and Nampula-Nacala. The TC2 estimates are constructed using yearly average transport costs plus a margin, and predict backward from 1996 to 2001 using the observed rate of growth from 2001 to 2004. These estimates are closer to existing observations for the cases of Pemba-Montepuez, Tete-Chimoio, and Xai-Xai-Chockwe.

It is important to point out that, when the price of diesel is included as an explanatory variable for predicting transaction costs, the estimated transaction costs increase significantly in the last year of the sample, due to the sharp rise in oil prices in 2004 and 2005. This implies, as we will see in the next section, a trend toward increasing market segmentation in the last period due to rising transport costs.

\subsubsection{Other considerations.}

The goal of the analysis is to focus on the implications of road rehabilitation for spatial market efficiency. Nevertheless, it is important to recognize that, similar to nearly all social science research, complete control of other factors is not possible. Rises in oil prices were mentioned in the previous paragraph. In addition, as discussed in Section 4, general processes of war recovery, economic growth, and agricultural market development following liberalization were ongoing during the estimation 

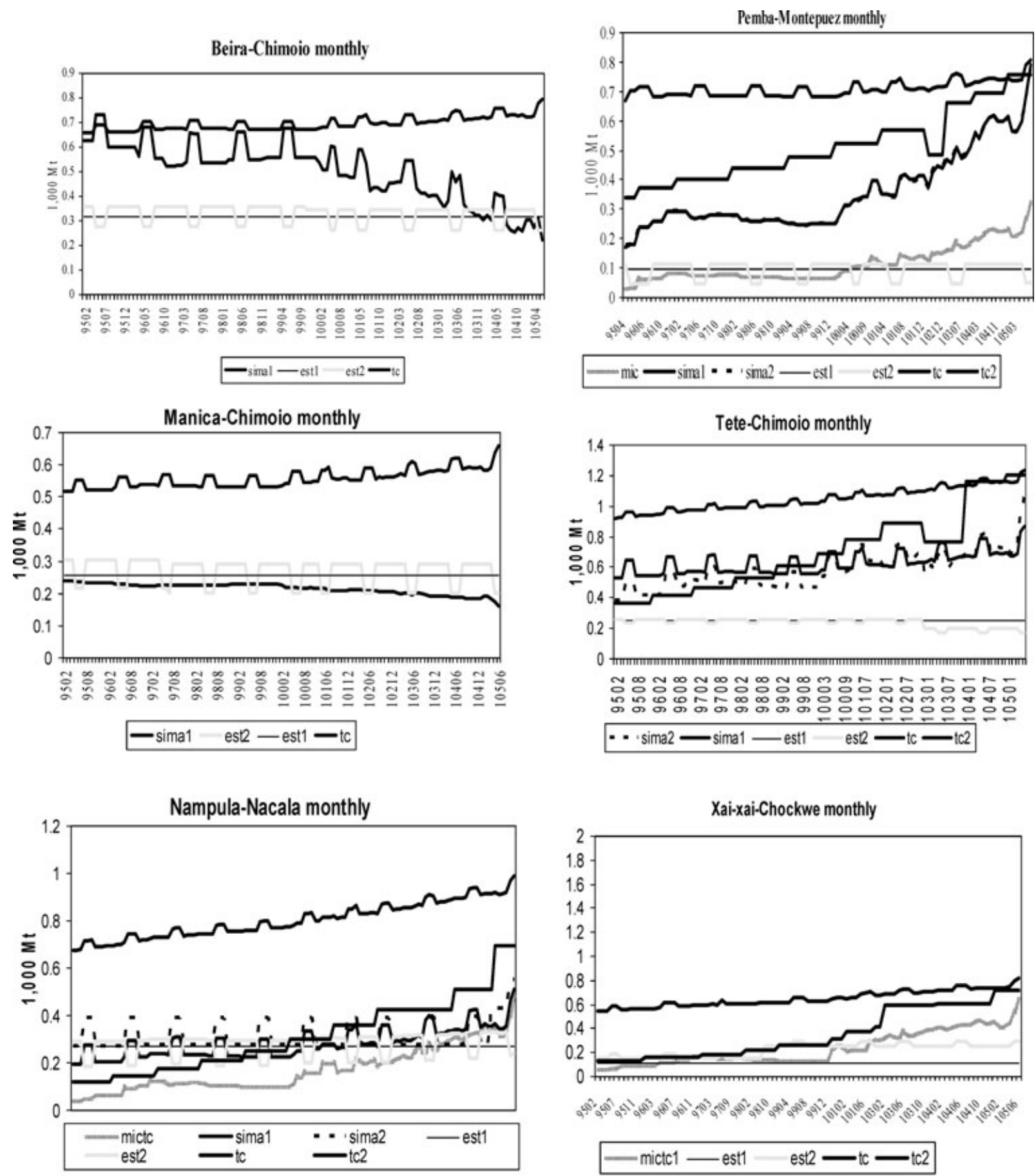

Note: Transaction costs defined in Table 3.

Fig. 3. Transaction costs by market pair.

period. These processes could be expected to lead to gradually enhanced market efficiency over time.

At the same time, the implications of road rehabilitation are often very substantial. Prior to road rehabilitation, road conditions may only permit low average speeds and require a four-wheel drive vehicle. After road rehabilitation, road conditions often allow for normal highway speeds. Given the importance of transfer cost and the importance of road quality for transfer costs, one can reasonably presume that road rehabilitation should be a large and detectable shock. 
Table 4

Summary statistics on price differentials before and after road rehabilitation

\begin{tabular}{|c|c|c|c|c|c|c|c|c|c|c|c|c|}
\hline \multirow[t]{2}{*}{ Markets } & & \multicolumn{5}{|c|}{ Price differential (absolute value) ${ }^{\mathrm{a}}$} & \multicolumn{3}{|c|}{ Before road rehabilitation } & \multicolumn{3}{|c|}{ After road rehabilitation } \\
\hline & & Obs & Mean & Std. Dev. & Min & Max & Obs & Average & Std. dev. & Obs & Average & Std. dev. \\
\hline \multirow[t]{2}{*}{ Beira-Chimoio } & Monthly & 118 & 0.418 & 0.264 & 0.027 & 1.43 & 57 & 0.484 & 0.243 & 61 & 0.355 & 0.27 \\
\hline & Weekly & 418 & 0.43 & 0.337 & 0 & 2.826 & 230 & 0.469 & 0.317 & 188 & 0.383 & 0.356 \\
\hline \multirow[t]{2}{*}{ Manica-Chimoio } & Monthly & 121 & 0.329 & 0.226 & 0 & 1.148 & 29 & 0.274 & 0.167 & 92 & 0.347 & 0.24 \\
\hline & Weekly & 459 & 0.323 & 0.291 & 0 & 2.57 & 123 & 0.276 & 0.246 & 336 & 0.340 & 0.304 \\
\hline \multirow[t]{2}{*}{ Nampula-Nacala } & Monthly & 121 & 0.367 & 0.312 & 0 & 1.369 & 114 & 0.353 & 0.301 & 7 & 0.603 & 0.406 \\
\hline & Weekly & 446 & 0.358 & 0.356 & 0 & 2.152 & 423 & 0.345 & 0.348 & 23 & 0.593 & 0.421 \\
\hline \multirow[t]{2}{*}{ Pemba-Montepuez } & Monthly & 88 & 0.339 & 0.22 & 0 & 1.22 & 66 & 0.35 & 0.221 & 22 & 0.308 & 0.219 \\
\hline & Weekly & 266 & 0.34 & 0.277 & 0 & 1.64 & 220 & 0.356 & 0.283 & 46 & 0.262 & 0.234 \\
\hline \multirow[t]{2}{*}{ Tete-Chimoio } & Monthly & 120 & 0.452 & 0.444 & 0.022 & 2.672 & 90 & 0.483 & 0.486 & 30 & 0.36 & 0.268 \\
\hline & Weekly & 425 & 0.465 & 0.505 & 0 & 3.65 & 319 & 0.492 & 0.551 & 106 & 0.387 & 0.319 \\
\hline \multirow[t]{2}{*}{ Xai-Xai-Chockwe } & Monthly & 89 & 0.496 & 0.367 & 0.048 & 1.916 & 35 & 0.604 & 0.467 & 54 & 0.426 & 0.267 \\
\hline & Weekly & 260 & 0.524 & 0.441 & 0 & 2.16 & 118 & 0.645 & 0.552 & 142 & 0.424 & 0.287 \\
\hline
\end{tabular}

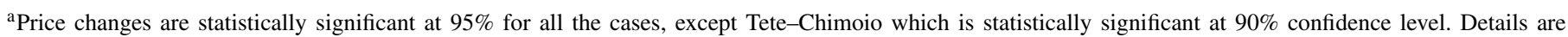
available upon request.

Source: Authors' calculations from SIMA.

Table 5

Estimated regime probabilities (monthly data)

\begin{tabular}{|c|c|c|c|c|c|c|c|}
\hline & & $\begin{array}{l}\text { Beira- } \\
\text { Chimoio }^{a}\end{array}$ & $\begin{array}{l}\text { Manica- } \\
\text { Chimoio }^{a}\end{array}$ & $\begin{array}{l}\text { Nampula- } \\
\text { Nacala }^{\mathrm{a}}\end{array}$ & $\begin{array}{l}\text { Pemba- } \\
\text { Montepuez }^{\text {b }}\end{array}$ & $\begin{array}{l}\text { Tete- } \\
\text { Chimoio }^{b}\end{array}$ & $\begin{array}{l}\text { Xai-Xai- } \\
\text { Chockwe }^{b}\end{array}$ \\
\hline \multirow[t]{2}{*}{ Efficient $\lambda_{1}$} & Before road rehabilitation & 0.001 & 0.08 & 0.146 & 0.001 & 0.045 & 0.112 \\
\hline & After road rehabilitation & 0.001 & 0.003 & 0.001 & 0.001 & 0.001 & 0.282 \\
\hline \multirow[t]{2}{*}{ Autarky $\lambda_{2}$} & Before road rehabilitation & 0.796 & 0.482 & 0.259 & 0.775 & 0.73 & 0.001 \\
\hline & After road rehabilitation & 0.796 & 0.334 & 0.337 & 0.998 & 0.932 & 0.504 \\
\hline \multirow[t]{2}{*}{ Inefficient $\lambda_{3}$} & Before road rehabilitation & 0.203 & 0.438 & 0.596 & 0.224 & 0.225 & 0.887 \\
\hline & After road rehabilitation & 0.203 & 0.664 & 0.662 & 0.001 & 0.007 & 0.215 \\
\hline LR Test ${ }^{\mathrm{c}}$ & & 0 & -1.002 & -2.672 & 5.682 & -2.112 & 22.49 \\
\hline
\end{tabular}

${ }^{a}$ Uses SIMA transaction costs estimates.

${ }^{\mathrm{b}}$ Uses TC2 transaction costs estimates (see Table 3 for definition).

${ }^{\mathrm{c}}$ Likelihood ratio test for significance of change in regime probability after rehabilitation completed $\left(\mathrm{H}_{0}: \gamma 1=\gamma 3=0\right)$.

Source: Authors' own calculations.

\section{Results}

Estimation of the model described in Eqs. (4) to (10) was carried out using both weekly and monthly data. There are advantages/disadvantages to each approach. On the one hand, weekly data provides a greater number of observations and a greater degree of price variation. On the other hand, it is difficult to assume that price differentials are arbitraged away on a weekly basis. In addition, monthly averages attenuate unusual large price differentials. In all cases, price differentials have been deflated using the national monthly CPI index.

The impact of road rehabilitation was proxied by a dummy with value 1 for the periods after road works were completed, and 0 otherwise. The implicit assumption here is that the full impact of the road improvement on efficiency is felt just after road works have finished. The dummy approach to measure the impact of road rehabilitation has at least two limitations. First, during the period of road works, transport cost may actually increase. Second, the impact of improvements in road conditions may be felt in nearby markets only after a time lag.
Nevertheless, in the absence of information regarding these two concerns, the dummy variable approach appears to be the most robust methodology.

Estimations were performed using GAMS with the Conopt solution algorithm applied. A likelihood ratio (LR) test was performed to test the null hypothesis of no change in probabilities after road rehabilitation (this is $\mathrm{H}_{0}: \gamma_{1}=\gamma_{3}=0$ in Eqs. (9) and (10)). ${ }^{9}$

Table 4 summarizes the main information regarding data availability associated with price differentials for every market pair. The timespan for most market pairs goes from 1995 to 2005. In addition, for the cases of Xai-Xai-Chockwe and Pemba-Montepuez, data from 2002 are much less frequent.

\footnotetext{
${ }^{9}$ For some market pair specifications when estimating endogenous transaction costs, parameters estimates tended to be unstable, likely to be the result of underidentification due to the large number of parameters to estimate and forcing some of the estimates to move to the bounds. With exogenous transport costs (a majority of cases and nearly all of our preferred estimations), convergence is robust.
} 

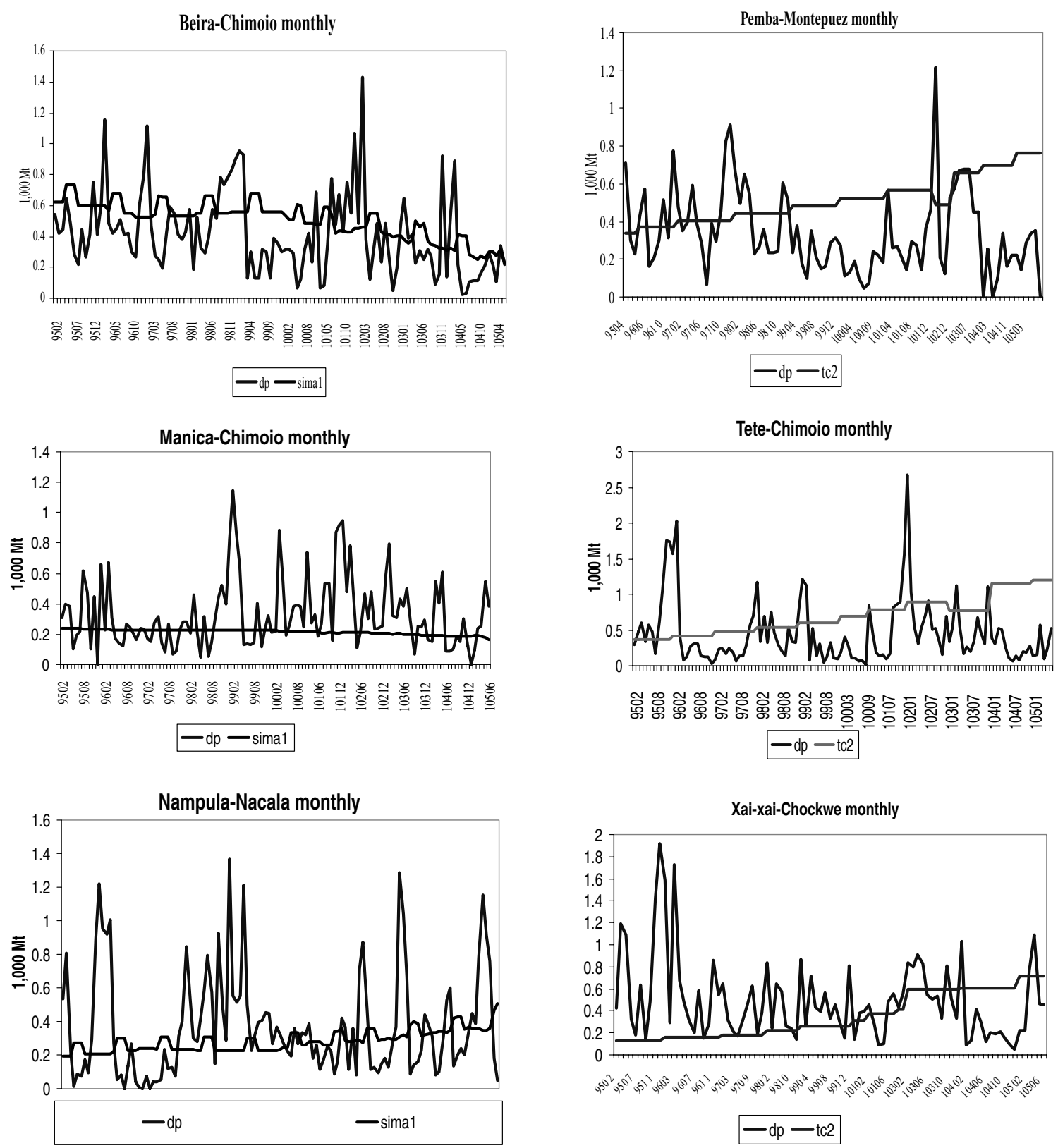

Note: dp - price differential; transaction costs defined in Table 3.

Fig. 4. Monthly price differentials and transaction costs by market pair.

\subsection{Main findings}

Price differences between the market pairs tended to decrease following road rehabilitation. Table 4 shows that, for the period after road rehabilitation was completed, the average price differential decreased for four of the six market pairs considered in this study.

Table 5 summarizes the main results that arise from the estimations of the extended PBM methodology. The table shows estimated regime probabilities before and after road rehabili- tation for each market pair. Fig. 4 plots the evolution of price differentials and transaction costs for each market pair. ${ }^{10}$

The main conclusion that surfaces is that the selected intraprovince markets do not tend to be spatially inefficient, with the exception of Manica-Chimoio and Nampula-Nacala, but tend to be in an autarky regime, where price differentials are not arbitraged due to high transport costs.

\footnotetext{
${ }^{10}$ A more detailed description of the results by market pair can be found in Cirera and Arndt (2006).
} 
Road rehabilitation should impact market functioning via two channels: reductions in transport costs and reductions in barriers to market entry particularly for small traders. Regarding the first channel, we only have transport costs observations before and after road rehabilitation for three market pairs. In these cases, total transaction costs actually increase following road rehabilitation primarily due to high fuel prices. This at least partially disguises the potential positive impact of road rehabilitation via reductions in transport costs. Regarding the second channel, despite the fuel price increases, we observe a reduction in average price spreads for all market pairs, except the inefficient Manica-Chimoio and Nampula-Nacala.

We test whether there is a change in regime probabilities before and after the month of road rehabilitation. This change is statistically significant for two of the six market pairs when we apply the likelihood ratio test. This could be interpreted as an indication that the impact of road rehabilitation is not large enough to change significantly regime probabilities after that period. Alternatively, the lack of significance may be associated with the steady increase in fuel prices in the final few years of data.

In summary, for most market pairs, the probability of inefficient regimes is reduced during the post-road rehabilitation period. The probability of the autarky regime increases roughly commensurately. While one expects (hopes) that road rehabilitation would lead to increased probability of the efficient regime, ceteris paribus, the increase in the autarky regime is consistent with the large increases observed in diesel prices, which appear to have offset the impact of road rehabilitation. In addition, we observed a reduction in average price spreads, excepting the two inefficient market pairs.

\section{Conclusions and policy implications}

Investment in infrastructure is one of the most significant policy actions taken by governments and donor agencies in order to facilitate market integration. Mozambique is no exception, and since the mid 1990s, after the war, very substantial investment has been devoted to road rehabilitation. This article contributes to the existing literature by trying to provide evidence of the impact of road rehabilitation on spatial market efficiency.

At the methodological level, we find that estimates from the extended PBM model are highly dependent on the quality of transaction cost estimates. In order to overcome this problem, we estimate a number of different transaction costs specifications that allow us to select best estimates and obtain more robust findings. Previous work typically employs a single set of transaction costs estimates (either exogenously supplied or endogenously estimated). Somewhat surprisingly, we find that, for the cases considered here, endogenous estimated transaction costs tend to underestimate "true" transaction costs thus biasing regime probabilities toward inefficient regimes.

Regarding the impact of road rehabilitation on spatial markets, we find that average absolute price differentials and inef- ficiency tend to decrease following road rehabilitation, with the exception of the pairs Manica-Chimoio and Nampula-Nacala. We do not find the probability of efficient trading increasing as the probability of inefficient regimes declines. Rather, market pairs have tended to shift toward autarky regimes. In two markets, changes in regime probabilities (a drop in the probability of inefficiency and commensurate rise in the probability of autarky in both cases) are statistically significant.

Overall, while the results point broadly toward a positive impact of road rehabilitation on spatial efficiency, they are not as strong or as robust as one would like, especially given the volume of road investment. Large increases in fuel prices during the post-road rehabilitation period likely contributed to the weakness of the results. The increase in fuel prices likely offset positive impacts of road rehabilitation on total transaction costs and contributed to the increase in the probability of being in an autarky regime.

In our view, the primary policy implication, arising as a result of the findings, is the continued need to facilitate market efficiency and market integration in Mozambique. In terms of transaction costs, road rehabilitation remains an instrument to reduce the transport cost component; however, other transport options, such as rail and maritime transport, should also be seriously considered, especially for longer distance routes. Future research may consider complementary initiatives to facilitate markets beyond transport infrastructure investment and provision of price information.

\section{Acknowledgments}

We would like to thank Guido Porto for encouragement and World Bank financial support in this project, Luis Matsinhe for assistance, and Karin Manente and Claudia Santos (WFP), Frans van de Ven (FAO), Danilo Abdula, Dr. Aquimo and Jorge Foquiço (ICM), and Eng Calado (ANE) for the information provided.

\section{References}

Abdula, D., 2005. Analysis of Vertical and Spatial Price Relationship Among Grain Markets in Mozambique. Ministry of Agriculture, Mozambique, Mimeo.

Barrett, C. B., 2008. Spatial market integration. In: Blume L. E., Durlauf S. N. (Eds.), The New Palgrave Dictionary of Economics, (2nd ed.). Palgrave Macmillan, London.

Barrett, C. B., Li, J. R., 2002. Distinguishing between equilibrium and integration in spatial price analysis. Am. J. Agr. Econ. 84(2), 292-307.

Baulch, B., 1997. Transfer costs, spatial arbitrage, and testing for food market integration. Am. J. Agr. Econ. 79(2), 477-487.

Cirera, X., Arndt, C., 2006. Measuring the Impact of Road Rehabilitation on Spatial Market Efficiency in Maize Markets in Mozambique, DNEAP Discussion Paper 30E. Ministry of Planning and Development, Mozambique. Available at http://www.mpd.gov.mz/gest/publicat. htm\#ANO\%20/\%20YEAR\%202006.

Donovan, C., 1996. Effects of Monetized Food Aid on Local Maize Prices in Mozambique, Ph.D. Dissertation, Michigan State University. 
Fackler, P. L., Goodwin, B. K., 2002. Spatial Price Analysis. In: Gardner B. L., Rausser G. C. (Eds), Handbook of Agricultural Economics. Elsevier Science, Amsterdam.

Jacobs Consultancy, 2005. Republic of Mozambique: railways and ports restructuring project. Transport Cost Study.

MIC, 2001. Analise dos Custos de Transporte na Comercializacao Agricola em Moçambique-Estudo de Casos dos Transportes de Milho das Zonas Norte e Centro para a Zona Sul de Mocambique. Ministerio da Industria e Comercio, DNCI No. 18.

Moser, C., Barrett, C. B., Minten, B., 2005. Missed Opportunities and Missing Markets: Spatio-Temporal Arbitrage of Rice in Madagascar, Mimeo.

Negassa, A., Myers, R., Gabre-Mhadin, E., 2003. Analyzing grain market efficiency in developing countries. Review of existing methods and extensions to the PBM Model. MTID Discussion Paper 63, IFPRI.

Park, A. F., Jin, H., Rozelle, S., Huang, J., 2002. Market emergence and transition arbitrage, transaction costs and autarky in China's grain markets. Am. J. Agr. Econ. 84(1), 67-82.

Penzhorn, N., Arndt, C., 2002. Maize markets in Mozambique: testing for market integration. Agrekon, 41(2), 146-159.
Samuelson, P., 1952. Spatial price equilibrium and linear programming. Am. Econ. Rev. 42, 283-303.

Sexton, R., Kling C., Carman, H., 1991. Market integration, efficiency of arbitrage and imperfect competition: methodology and an application to US celery. Am. J. Agr. Econ. 7, 568-580.

Sistema de Informacâo deMercados Agrícolas (SIMA), 2005. Electronic Database. Ministry of Agriculture and Rural Development, Maputo.

Spiller, P., Wood, R. O., 1988. The estimation transaction costs in arbitrage models. J. Econometrics 39, 568-580.

Takayama, T., Judge, G. G., 1971. Spatial and Temporal Price Allocation Models. North Holland, Amsterdam.

Tarp, F., 1990. Prices in Mozambican agriculture. J. Int. Devel. 2(2), 172-208.

Tarp, F., Arndt, C., Jensen, H. T., Robinson, S., Heltberg, R., 2002. Facing the Development Challenge in Mozambique: An Economywide Perspective. IFPRI Research Report 126, International Food Policy Research Institute, Washington, DC.

Tostao, E., Brorsen, B. W., 2005. Spatial efficiency in Mozambique's postreform maize markets. Agr. Econ. 33(2), 205-214.

World Food Programme, 2005. Informal cross border food trade in Southern Africa. FEWS NET 10 